\title{
La formación para el trabajo de los jóvenes desde las organizaciones de la sociedad civil en América Latina y el Caribe
}

\author{
Cristina Girardo* \\ María del barrola*k
}

\begin{abstract}
Resumen: En este artículo se aborda el estudio de las organizaciones de la sociedad civil como agentes innovadores en la ejecución de programas para la formación del trabajo dirigida a jóvenes, aludiendo a las formas, los modelos y los cambios que las políticas de formación para el trabajo tuvieron en América Latina, y en el Caribe. En el plano teórico se destaca la importancia del espacio local y las políticas de descentralización, como producto de las reformas del Estado, y la innovación en la gestión de los municipios, por constituir el marco en el cual se desarrollan y actúan las OSC, que se suman a la idea del espacio público desde una nueva concepción: como una interacción entre esferas privadas y estatales. Se describen así mismo las características de las organizaciones estudiadas: su perfil institucional, la población atendida, así como los enfoques, estrategias de intervención y diseño de instrumentos que las caracterizan. Se analiza también el caso de México y sus especificidades.

Palabras clave: jóvenes, desarrollo local, descentralización, formación para el trabajo, organizaciones de la sociedad civil.
\end{abstract}

\begin{abstract}
A bstract: The study of Non Governmental Organizations (NGOs) is undertaken in this article. They are understood as innovative agents for the design and implementation of specific vocational training programs for young people within the changes in the National vocational education and training policies that took place in Latin America an the Caribbean in the last decade, which are briefly described in this text. The importance of local space and decentralization policies, resulting from the reforms of the Latin American Estate, and the innovation in the management of local governments is the context in which NGOs develop and function. NGOs are part of the idea of a new public space created by the interaction between private and estate spheres. Selected Mexican NGOs operating in a local space and training young people, who otherwise have no other training opportunities are described: their general characteristics, their institutional profile, the population they serve, the approaches, strategies and instruments of their intervention.

Key words: Young people, local development, decentralization, vocational training, Non Governmental Organizations.
\end{abstract}

*Programa deEstudios del Tercer Sector, El Colegio M exiquense, A .C., correo electrónico: girardo@prodigy.net.mx

**Departamento de Investigaciones Educativas, CINVESTAV-M éxico, correo electrónico: mibarrola@mx.inter.net 


\section{Introducción}

Las políticas y los modelos de formación para el trabajo desarrollados en A mérica Latina y el Caribe han sido objeto, en estos últimos años, deun renovado interés y deprofundos cambios: identificación denuevosusuarios, desarrollo de nuevos enfoques para atender situaciones complejas, surgimiento de nuevos actores, modificaciones en los desempeños e interacciones entre nuevos y viejos actores (De Ibarrola, 1999b; Leite, 1999; 2002). Todas estas dimensiones sedeterminan mutuamentey configuran innovaciones muy importantes para la formación de los jóvenes para el trabajo en América Latina y el Caribe, en particular de aquellos identificados en riesgo de exclusión social (Jacinto y Gallart, 1998; Jacinto, 1999; Pieck, 2000).

Frente a la crisis de las instituciones clásicas de formación para el trabajo imperantes en la región, y pese a los esfuerzos llevados a cabo durante años por los gobiernos y sus instituciones (capacitación para el trabajo, educación media técnico-profesional, formación superior en centros de formación técnica, institutos de formación profesional y universidades tecnológicas), aparece hoy una gran variedad de organismos interesados y activos en el tema: diversos ministerios y dependencias internas a los mismos, organismos a escala regional o municipal, sindicatos, asociaciones empresariales, despachos privados y, en particular, un grupo importante de organizaciones cuyas características comportan una nueva institucionalidad y se manifiestan como una experiencia sobresal iente de A mérica Latina y el Caribe: las organizaciones de la sociedad civil (osc). Estas últimas se presentan como las organizaciones más novedosas y a la vez menos estudiadas por la investigación académica, razón por la cual consideramos su estudio imprescindible para entender nuevos enfoques y funciones innovadoras que estas organizaciones desarrollan como parte sustantiva de las actuales políticas de formación para el trabajo.

Los resultados presentados en este artículo forman parte de una investigación más ampliafinanciada por el Consejo Nacional deCiencia y Tecnología (Conacyt) titulada "La formación de los jóvenes no universitarios para el trabajo, en el desarrollo regional de México" 
real izada durante 1999-2002. ${ }^{1}$ La investigación general tuvo como propósito principal lograr un salto cualitativo, tanto de naturaleza teórica como metodológica, respecto de las investigaciones sobre las relaciones entre la educación y el trabajo y centrar la mirada de los investigadores, de manera abierta, sobre todo lo que pasa en una ciudad en materia de formación de sus jóvenes para el trabajo. Desdeel principio, y con base en una amplia bibliografía latinoamericana al respecto (Tokman, 2004; Ramírez, 2004; Jacinto, 1999; 2000; 2001; 2002; Gallart, 1998; 2000; 2001; 2002; 2004; Pieck, 2001; 2002), se precisó la importancia de investigar la posible presencia de organizaciones de la sociedad civil como actores importantes en la formación para el trabajo de los jóvenes.

Para encuadrar y orientar esa parte de la investigación se analizaron previamente experiencias Ilevadas a cabo por organizaciones de la sociedad civil, de prestigio y reconocimiento internacional, ${ }^{2}$ junto con experiencias que tuvieran que ver, específicamente, con desarroIlo local. ${ }^{3}$ Por otra parte, para el caso deM éxico setomó como referencia experiencias desarrolladas por diferentes organizaciones en distintas ciudades. ${ }^{4}$ Las organizaciones fueron sel eccionadas después

\footnotetext{
${ }^{1}$ Diseño y dirección general de María de Ibarrola. Cristina Girardo participó en el proyecto con el estudio sobre las organizaciones de la sociedad civil que contribuyen a la formación para el trabajo de los jóvenes en la ciudad. Su investigación “La formación para el trabajo de los jóvenes (desafíos y estrategias) desde las organizaciones de la sociedad civil", constituyó su tesis de doctorado en el Centro de Estudios Latinoamericanos de la Facultad de Ciencias Políticas de la Universidad Nacional Autónoma de M éxico (UNAM). La doctora María de Ibarrola fue directora de la tesis (marzo de 2003).

2 Paisa Joven de Colombia, Foro Juvenil de Uruguay, Centro de Profesionales para la Acción Comunitaria y la Escuela de Formación Profesional en Oficios de la Fundación Cristo Vive, de Chile; Viva Río de Brasil y el Polígono Industrial Don Bosco de El Salvador.

3 Para ello nos detuvimos en el análisis de Paisa Joven en Medellín (Colombia), Foro Juvenil en Montevideo (Uruguay), dos experiencias en comunas de Chile: Lo Espejo y El Bosque y Crisol en tres localidades de Argentina (Arrecifes, Salto y Pérez Millán).

${ }^{4}$ Instituto Poblano de Readaptación, A.C. (Ipoderac); el Fondo de Valle Bravo y Solidaridad (Fovaso); la Coordinadora de Comunidades y Ejidos Forestales del Estado de Oaxaca y el Centro de Estudios sobre el Desarrollo Rural (Cesder); Centro de Investigación y Promoción Educativa y Cultural, A.C. (CIPEC) y la Cámara de la Industria del Calzado del Estado de Guanajuato (CICEG).
} 
de haber revisado diferentes directorios locales, estatal es y nacionales de organismos de la sociedad civil que trabajan el tema. Con la información recabada se eligieron las organizaciones que cubrían los siguientes requisitos: ser organizaciones civiles legalmente constituidas; tener entre sus objetivos, sino es que el más importante, impartir formación para el trabajo y que atendieran a jóvenes entre 15 y 29 años. Seaplicaron entrevistas semiestructuradas y focal izadas durante todo el año 2000 a informantes claves de cada organización. También serecabó folletería y todo tipo dedocumentación, lo cual permitió ampliar nuestra información respecto a las actividades y los programas de las organizaciones seleccionadas.

En la primera parte deesteartículo, queengloba los cuatro siguientes apartados, se aborda la importancia del espacio local y las políticas de descentralización como producto de las reformas del Estado, así como la innovación en la gestión de los municipios por constituir el marco en el cual se desarrollan y actúan las osc, que se suman a la idea del espacio público desde una nueva concepción: como una interacción entre esferas privadas y estatales. A continuación se describen las características de las organizaciones estudiadas: perfil institucional, población atendida, así como los enfoques, las estrategias de intervención y el diseño de los instrumentos que las caracterizan. Seanaliza posteriormenteel caso de México y sus especificidades.

En la segunda parte se evidencian las fortalezas y debilidades de las osc estudiadas, para determinar, en primer lugar, cuáles son las oportunidades preval ecientes en $\mathrm{l}$ entorno en dondedesempeñan sus funciones las osc de formación para el trabajo y, en segundo lugar, cuáles son las amenazas que perturban el desarrollo de las mismas. Por último, se presentan las condusiones como consideraciones finales del trabajo.

\section{La importancia del contexto local}

El espacio local se presenta como escenario privilegiado para el desarrollo de las políticas deformación para el trabajo y para la actuación de las osc a escala. 
Identificar el estudio delo local presupone considerar las políticas de descentralización como producto de las reformas de Estado (Cabrero Mendoza, 1995; Rivera Roy, 1996; Coraggio, 1997), la innovación en la gestión de los munici pios y los procesos de desarrollo local (Borja, 1987; García Del gado, 1998) que son, ante todo, una estrategia que toma como mecanismo dinamizador los procesos de desarrollo endógeno, esto es, el impulso de la capacidad emprendedora local, las acciones de capacitación de potenciales creadores deempresas, las políticas de formación para el trabajo, las estrategias cotidianas que generan aprendizajes, las iniciativas de las instituciones locales en materia socioeconómica, losllamados polos dereconversión, mediante una cooperación entre agentes públicos y privados (Vázquez Barquero, 1993).

De manera paradójica, en la fase de la globalización, junto con la integración mundial y el desvanecimiento de fronteras económicas, surge una tendencia a impulsar y fortalecer lo local y regional (Girardo, 2003). Al mismo tiempo, la revalorización de los sistemas de gobierno democráticos señala al municipio como un ámbito más próximo a la ciudadanía y por tanto como espacio privilegiado para la construcción de la democracia social. Deesta manera, lo local-municipal asume un significado nuevo como espacio para la participación, el ejercicio de derechos ciudadanos y la planeación con sectores políticos y económicos, pero a su vez como espacio delocalización del capital trasnacional.

La importancia de lo local como instancia privilegiada para el desarrollo de las políticas de formación para el trabajo nos remite por Io menos al análisis de tres dimensiones: a) una de carácter espacial; b) una de carácter institucional; y c) otra de carácter social.

La primera, o sea la lógica de carácter espacial, nos vincula a su vez a la temática de la descentral ización, en el entendido de que esta última contieneel nivel de lo local como una de sus dimensiones esenciales. Cabe advertir que la descentralización por sí misma no establece mecánicamente condiciones de cambio, tampoco crea, con sólo establecer una reforma político-administrativa, el escenario para implantar cambios en el desarrollo de políticas públicas ni el ambiente para la articulación de los diversos actores e intereses económicos que actúan en el territorio. Sin embargo, el reconocimiento e impulso de la 
dimensión espacial local rompe con los paradigmas clásicos del proceso regido por los estados central izados y federales y hace obsol etas muchas de las estrategias tradicionales de la capacitación laboral inicial. Para ello, sin embargo, necesita encontrarsecon procesos quetienen que ver con el capital social desarrollado en el territorio, con una identidad y una atmósfera, en donde precisamente la descentralización y la función de todos los actores (gobierno-empresa-sociedad civil) podrán poner en práctica mecanismos que identifiquen, por la cercanía, las necesidades del territorio.

Las dimensiones institucional y social permitirán a su vez, articular posibilidades de intervención de manera directa en las principales decisiones y gestiones del desarrollo.

Estas dimensiones evidencian la participación de múltiples agentes públicos y privados en este espacio local, sin negar la participación de una instancia central-nacional que debe asumir funciones de integración y regulación. De esta manera se está proponiendo como paradigma institucional un sistema de formación para el trabajo que tenga en cuenta la participación de distintos actores de la sociedad.

Sin perjuicio que la implementación de una política de empleo y productividad de jóvenes debe ser impulsada, orientada y apoyada con recursos desde el Estado en sus niveles nacionales, así como debe contar con la participación comprometida y legitimizadora delas organizaciones sociales y empresariales del mismo nivel, la concreción práctica de las cadenas de agentes formativos y de soporte institucional necesarias para estructurar laformación detransición sólo serealiza en el nivel local (Ramírez Guerrero, 1998:269).

Las instituciones vinculadas con la formación para el trabajo han tardado en reconocer que la escala local es la más adecuada para relevar, vincular y articularse con sus objetivos. Tal reconocimiento está relacionado con la estructura productiva desarrol lada en un territorio particular quele permitearticular model os degestión acordes con las necesidades del lugar. En términos de gestión pueden diseñar y gestionar sus programas en relación con la vida cotidiana y con las actividades económicas productivas de la localidad, rescatando toda una 
seriedeconocimientos tácitos pertenecientes al contexto y a la cultura del sitio.

Las organizaciones de la sociedad civil son heterogéneas y representan a distintos sectores organizados de la población. Algunas están más vinculadas con el sector empresarial (las cámaras y las fundaciones), otras con sectores de la Iglesia (organizaciones de bases, eclesiásticas), y otras más son organizaciones barriales que representan los intereses de los vecinos, centros comunitarios, de promoción y desarrollo, de defensa de los derechos, etcétera. Todas desarrollan proyectos y modelos de intervención diversos, como ve remos en párrafos posteriores. El desarrollo local -en principio- está planteado como un proyecto común que combina un proceso de concertación de los diversos agentes de un municipio, con crecimiento económico, mejora socio-cultural y con el objetivo de el evar la calidad de vida de las personas que viven e interactúan en el territorio, pero a su vez desarrolla una capacidad competitiva propia para insertarse en el mercado globalizado.

Sin embargo, a pesar del consenso acerca del nuevo protagonismo de distintos actores que actúan en el espacio local, hay matices importantes o desacuerdos acentuados a la hora de sopesar los distintos actores que influyen en el desarrollo de lo local y la potencialidades deciertas formas degovernance (Hualde, 2002). La complejidad deriva de la multiplicidad de actores que confluyen en el accionar, lo que trae como consecuencia fuertes conflictos cuando no se observa un proyecto común, generando enormes desigualdades. Asimismo se dificulta aprehender las distintas lógicas con que actúa cada actor. El poder desigual de los actores locales, frente al de los regionales, nacionales o internacionales y su capacidad de impulsar el desarrollo local con eficiencia, todavía es objeto de discusión y debate entre los especial istas.

\section{Surgimiento y protagonismo de las OSC en América Latina y el Caribe}

En estos últimos años, procesos trascendental es quetuvieron lugar en A mérica Latina y el Caribe-como la pérdida de eficacia de las for- 
mas económicas tradicionales de orden corporativo y tradicional, las crisis en los paradigmas de desarrollo, el intenso cuestionamiento político a los gobiernos por corrupción y autoritarismo, la clara insuficiencia e ineficiencia de la acción gubernamental para la solución de problemas, entre otros- permitieron el surgimiento de organizaciones civiles que actúan en la esfera pública junto al sector estatal. Este actor emergente constituye una alternativa organizada a la crisis que presentan las organizaciones tradicionales, pertenecientes ya sea al Estado, o bien al mercado. El Estado ya no se presenta como el único ámbito de institucionalización del conflicto y de canalización de demandas. Ya no constituye, como en la visión iluminista, el ámbito exclusivo de definición del bien común, o, en términos hegelianos o durkheimnianos, el lugar en que se define o negocia el bienestar general. El sistema político y la burocracia estatal ya no se muestran, tampoco, como la clase universal que se erige por los particularismos anímicos de la sociedad civil. El mercado, por su parte, estimula el surgimiento de distintas organizaciones, dirigidas a la obtención de un interés de naturaleza privada.

En este contexto, la sociedad civil ha generado mecanismos de encauzamientos de conflictos y demandas y ha comenzado a colocar en la agenda pública distintas problemáticas que suponen la defensa del bienestar general y dela democracia así como dela convivencia y del respeto a las particularidades. Se hace evidente entonces una pluralidad de reivindicaciones no llevada antes a cabo en el espacio público.

La participación denuevosactores sociales o la preponderancia que han adquirido en las décadas recientes del sigl o xx, como formas inéditas derelacionarsey organizarse, encuentran sus causas en las crisis de las estructuras centralizadas, derivadas del tipo de Estado imperante en las regiones. Las democracias populistas, autoritarias y corporativistas habían establecido prácticas políticas como el clientelismo y la corrupción, involucrando a la sociedad civil sólo en una lógica corporativa y burocrática y rompiendo los mecanismos de relacionalidad, reciprocidad y solidaridad.

Desde losúltimos treinta años del siglo pasado, en América Latina y el Caribelas osc forman partedeuna amplia corrientedela sociedad 
civil que fue construyéndose desde abajo, desde los márgenes de la sociedad y desde actores poco reconocidos reclamando espacios políticos negados por un gobierno corporativo. Muchas de ellas nacieron vinculadas a movimientos sociales, hasta transformarse en portadoras de demandas sociales propias y críticas al gobierno. Las prácticas por construir nuevos escenarios políticos, ampliar una democracia más participativa y conformar nuevas instituciones electorales constituyeron en sí mismas las causas por las cuales las organizaciones civiles desplegaron cada vez más su actividad.

Es así como las organizaciones de la sociedad civil, queya operaban desde hacía tiempo en la región, empiezan a ser identificadas y reconocidas como posibles actores para el suministro de al gunos servicios públicos como atención a niños en situación de calle, a excluidos del sistema escolar y prevención de drogas, entre otros (sehacevisiblesu función en la formación para el trabajo). Se gesta, de esta manera, un model o que transfiere al sector público no estatal, o a entidades gubernamentales que hasta ahora habían operado directamente, ciertos servicios o incluso la operación de programas y funciones concretas, al tiempo que el Estado continúa manteniendo las responsabilidades básicas de diseñar, financiar y evaluar esos servicios.

En el caso concreto dela formación para el trabajo delosjóvenes en riesgo deexclusión, la modalidad preferente en varios países se configuró mediante la licitación pública de programas que se abrían a la participación de diversos tipos deactores. Deesta manera se empezaron a establecer convenios con distintas instituciones (empresas, iglesias, organizaciones sociales, etcétera), lo que permitió diversificar y ampliar la oferta, al diseñar ésta en función dela demanda o el estudio de necesidades reales, creando mecanismos de ejecución del egada de programas, en los que se transfieren fondos públicos, y propiciando mayores y mejores relaciones entre los organismos ofertantes y diversos grupos empresariales, potenciales empleadores de los jóvenes así formados.

Dadas las limitaciones administrativas técnicas del aparato deEstado de los países latinoamericanos - y en esto también hay, desde luego, importantes diferencias de grado-, refor- 
zadas en los años ochenta por la escasez de fondos públicos característica de períodos de ajuste fiscal como los que atravesaba la región en esos tiempos (Navarro, en Bresser Pereira y otros, 1998:101).

Puede argumentarse que muchos programas nacionales de gran magnitud, como el Plan N acional deEducación Profesional delosTrabajadores (Planfor) ${ }^{5}$ en Brasil, Proyecto Joven ${ }^{6}$ en Argentina o Chile Joven, ${ }^{7}$ en Chile, no hubiesen sido desplegados de la manera oportuna y eficienteen quelo fueron, y en al gunos casos ni siquiera hubiesen sido lanzados exitosamente, de no haberse producido la entrada en

\footnotetext{
${ }^{5}$ Estructurado e implantado a partir de 1995, Planfor impuso un rumbo nuevo a la educación profesional, tratándola como una cuestión de política pública, reconociendo a nuevos sujetos de formación, en particular desempleados, del sector informal, jóvenes en riesgo de exclusión, movilizando a nuevos actores y actuando en la construcción de una nueva institucionalidad de la educación profesional en el país. El plan tiene como objetivo global articular de manera gradual toda la capacidad dela educación profesional existente en el país y propiciar anualmente calificación y recalificación de al menos $20 \%$ de la población económicamente activa (PEA) mayor de 14 años. Si consideramos que la PEA brasileña está constituida por al rededor de 75 millones de trabajadores mayores de 14 años (entre ocupados y desocupados, mercado formal e informal), el 20\% equivaldría a 15 millones de trabajadores. En 1996 atendió a 2.614 municipios y en 1997 a 3.843 (en el país hay un poco más de cinco mil municipios).

${ }^{6}$ Proyecto Joven en Argentina se inició en 1994 con el apoyo del Banco Interamericano de Desarrollo (BID). El proyecto imita a su contraparte chilena en el sentido de utilizar la formación como un medio para aumentar el empleo entre los jóvenes, particularmente de los estratos de bajos ingresos. Al formar a estos jóvenes, el programa intenta incrementar su productividad e infundirles valores y actitudes apropiadas, habilidades y valores que, a su vez, se supone que mejoran sus oportunidades de obtener y mantener un trabajo. Dirigido a 170 mil jóvenes provee fondos al ministerio de Trabajo para contratar formación con cualquier institución confiable, ya fuera pública, privada o dela sociedad civil (Castro C. DeM oura, 2002).

${ }^{7}$ Chile Joven es una experiencia llevada a cabo en Chile sobre formación para el trabajo de los jóvenes. Podemos señalar que este programa se comenzó a ejecutar en 1992 financiado por el Banco Interamericano de Desarrollo y, a partir de 1996, con recursos del presupuesto nacional. Los agentes que participaron en estos programas fueron: el Estado en el diseño global de los programas; la ejecución de los cursos se delegó a una diversidad de actores institucionales y organizaciones públicas y privadas. La evaluación y supervisión sellevó a cabo con fondos del presupuesto nacional.
} 
escena de nuevos actores y el cambio de roles de los preexistentes. Aunque si bien, como lo plantea Claudia Jacinto (1999), la transformación de la función del Estado y, especialmente, de sus organismos central es responsables de la formulación de políticas supone transferencias y responsabilidades, esto no implica (por lo menos necesariamente) quese debilite. Se produce un aumento de la participación en las políticas de los beneficiarios, de la sociedad civil, de los organismos locales y de las organizaciones de mercado, aunque el protagonismo del Estado sigue siendo fundamental.

Otra de las causas queexplican por quéa partir de la década de los ochenta comienzan a participar las organizaciones de la sociedad civil, principalmente las $\mathrm{ONG}^{8}{ }^{8}$ en las políticas de formación para el trabajo, la encontramos en la evolución y transformación de su gestión interna, que les permite responder de manera ágil, eficientey oportuna a las posi bilidades que ofrecía la reforma del Estado.

En un primer momento las oNG desempeñaban sus funciones fundamental mentecomo actores demovilización política. Otro rasgo importante es que fueron los principales agentes de canalización de recursos financieros extranjeros para la ejecución de programas sociales vinculados con el desarrollo, en particular en los países que vivieron dictaduras. La acción de las ong como proveedoras de servicios social es y de acciones conjuntas o de al guna manera apoyadas o coordinadas con programas estatales, en estecaso en programas decapacitación laboral, es una innovación, producto del proceso queempezó a ser recorrido por las organizaciones en estos últimos años. Si bien este

\footnotetext{
${ }^{8}$ En la región es común denominar a estas instituciones ONG, y no organizaciones de la sociedad civil (osc) como las hemos Ilamado en nuestro trabajo. El término ONG es más conocido y usado a nivel internacional por su capacidad para englobar a todas las organizaciones no gubernamentales. Si bien es un término que tuvo sus orígenes vinculado con la cooperación internacional, usado primero en la Liga de Naciones Unidas y posteriormente en la Organización de las Naciones Unidas (ONU), fue adoptado después por todos los países beneficiarios de la cooperación. Esto ocasionó una gran confusión en la identidad de las organizaciones, ya que, como decíamos anteriormente, se generalizó su uso hasta abarcar organizaciones y modos de actuar que muchas veces no responden a esta forma jurídica (Girardo, 2003).
} 
proceso ha atravesado por diversas etapas y marchado a diferentes ritmos en cada país, se habla ya de un nuevo paradigma cuando se aludea las ong (por sus métodos de gestión, por la forma deal legarse recursosfinancierosy por su nueva relación con el gobierno) (Reygadas, 2002).

Dichas modificaciones sellevan a cabo casi siempre como respuesta a la iniciativa del Estado, de los nuevos gobiernos democráticos, que llama a las ong a incorporarse al esquema de la política social. La entrada en procesos decooperación no ha sido inmediata, fácil ni generalizada. Los gobiernos han debido hacersemerecedores dela confianza delas ong y éstas a su vez aprovechado la oportunidad para lograr el reconocimiento desus operaciones einfluencia, desu carácter deactores válidos decara al Estado así como dela posibilidad de expandir su basederecursos. Esta combinación de esfuerzos haterminado por vencer resistencias ideológicas y políticas muy presentes en las organizaciones. A pesar desu muy limitaday, en muchos casos, aún superficial relación decooperación, sehainiciado una nueva etapa dela forma en que ambos sectores conciertan intereses entre sí sobrela base del bien público.

Por último, encontramos como causa importante de la participación de estas organizaciones en la prestación de servicios públicos, su experiencia y familiaridad en la atención a una gran cantidad de trabajadores que con los sistemas deformación tradicionales habían quedado sin atender: los desempleados, los marginales, todos los trabajadores del sector informal dela economía, las mujeres y los jóvenes excluidos tempranamente del sistema escolar. En efecto, en general en América Latina y en el Caribe los programas llevados a cabo por instituciones del Estado han protegido y han sido dirigidos a los trabajadores más organizados -en particular de las clases medias y los sindicalizados-, dejando al margen una considerable proporción depoblación trabajadora en el sector informal, así como a grupos más necesitados severamenteexcluidos.

Las organizaciones de la sociedad civil centraron siempresu atención en este último sector de la sociedad, como veremos en el siguiente apartado. Sus actividades, además, siempre tuvieron que ver con poblaciones marginadas, con serios problemas de inserción 
y desarrollo. La legitimidad que tenían en las comunidades, por su acción y formas de operar, por la cercanía que estaban acostumbrados a tener con los usuarios de sus servicios, por la integralidad o carácter humano y personalizado que le imprimen a los servicios que prestan, las convirtió en un referente significativo para ejecutar políticas vinculadas con programas gubernamentales.

\section{Características de las organizaciones estudiadas}

En esteapartado desarrollaremos el perfil institucional delas osc y los enfoques, las estrategias deintervención y los diseños deinstrumentos delos programas de formación para el trabajo.

a) Perfil institucional y población atendida

Podemos clasificar en cuatro grupos a las osc que se dedican a la formación para el trabajo de los jóvenes en A mérica Latina y el Caribe:

Un primer grupo lo constituyen las cámaras empresariales, ${ }^{9}$ las asociaciones de comerciantes, los comités de productividad einnovación tecnológica y los centros para el desarrollo y competitividad de las empresas. Son organizaciones formadas y más vinculadas con grupos dirigentes y con intereses dela claseempresarial (son los empresarios quienes forman parte deestas organizaciones). Al gunas cámaras y asociaciones deempresariosyahabían participado ampliamenteen el asunto de la formación para el trabajo, en especial mediante su participación en la gestión de los sistemas e institutos de formación profesional. El desarrollo y la ejecución de programas de capacitación por parte de los empresarios se ha ido ampliando en estos

\footnotetext{
9 Por ejemplo la Federación de las Industrias de Río de Janeiro (Forjan) en Brasil, la Cámara Chilena de la Construcción, en Chile, en Venezuela, la iniciativa de las empresas del Grupo SIVENSA, mediantela Fundación Fundamental. En Argentina, las empresas nucleadas en la Cámara de la Industria Gráfica, por medio de la Fundación Gutenberg. En México, la Cámara Nacional de la Industria Textil, la Cámara Nacional de la Industria de la Construcción y la Cámara de la Industria del Calzado en León, Guanajuato, son algunas que podemos citar bajo este perfil.
} 
últimos años, producto de las innovaciones tecnológicas, los cambios en la organización de las empresas y por las nuevas competencias demandadas a los trabajadores. Estas organizaciones representadas por las cúpulas empresariales empezaron a reforzar sus programas institucionales para elevar la productividad.

En muchos casos el origen de sus recursos se conforma a partir de las cuotas que aportan sus asociados y sustentan actividades decapacitación que responden a las demandas específicas de sus empresarios afiliados. Desarrollan también programas dirigidos a la micro, pequeña y mediana empresa, ${ }^{10}$ ya que al gunas de las grandes empresas llevan a cabo su propia capacitación. La población atendida responde generalmente a obreros ya calificados, cuadros medios y personal directivo, y sus beneficiarios son personas ya insertas en el mercado de trabajo. Diversas investigaciones coinciden en señalar que estas empresas tienden a capacitar a su personal más escolarizado (Novick, 1999, 2002; Ramírez, 2004). Este tipo de organizaciones también tienden a ser seleccionadas como ejecutoras de los programas financiados y concertados con las secretarías y ministerios de Trabajo, en buena medida con el fin de evitar los recortes de personal en las mismas.

Un segundo grupo lo constituyen organizaciones dela sociedad civil, Ilamadas "corporativas" o "de segundo piso", como Foro Juvenil ${ }^{11}$

${ }^{10}$ Como el desarrollado por el Servicio de A poyo a Micro y Pequeñas Empresas (Sebrae).

${ }^{11}$ Foro Juvenil es una organización privada, sin fines de lucro, fundada en 1981, dedicada a la promoción, investigación y consultoría en temas de adolescencia y juventud en Uruguay y a nivel regional. Su finalidad es contribuir a la creación y consolidación de condiciones equitativas para la inserción protagónica de los y las jóvenes en la sociedad. Sus objetivos institucionales son: a) producir conocimientos sobre la realidad juvenil, abordándola tanto global como sectorialmente, o en relación con áreas problemáticas; b) desarrollar y sistematizar experiencias piloto de promoción juvenil en temas estratégicos; c) elaborar y realizar con otros actores públicos y privados proyectos de mediano alcance que respondan a los principales problemas juveniles; d) comunicar la información y la reflexión institucional, sensibilizando a la opinión pública en general y a sectores vinculados a la realidad juvenil en especial. Los temas principales en los cuales trabaja son: educación y trabajo (formación para el trabajo e inserción laboral), apoyo a pequeñas y medianas empresas juveniles, niños y jóvenes urbanos en desventaja social, cultura juvenil, juventud rural, juventud y cooperativismo, intercambio ju- 
en Uruguay y Paisa Joven ${ }^{12}$ en Colombia. En estas organizaciones la capacitación laboral tiene una gran importancia dentro de sus objetivos, motivación de su participación y actividades. Están formadas generalmente por personal capacitado y establecen relaciones y alianzas con otras instituciones para la ejecución de sus programas. Además de recibir financiamiento de organismos internacionales, dichas organizaciones participan en concursos y licitaciones otorgados por los Estados. Se caracterizan asimismo por atender a población marginada, en situación de pobreza y excluidos del sistema escolar.

Un tercer perfil institucional está compuesto por las organizaciones que tienen vínculos o pertenecen a la Iglesia católica, por lo general

venil a nivel nacional, regional e internacional y programa de apoyo a residencias estudiantiles (Jacinto, 1997:79).

12 Paisa Joven es una corporación mixta, sin fines de lucro, cuya constitución legal tuvo lugar en 1994, en Medellín, Colombia. Contó con la asistencia técnica de la A gencia de Cooperación del Gobierno Alemán (GTZ). Es una organización de "segundo piso", es decir, no es ejecutora directa de acciones ni está concentrada en el fortalecimiento institucional de sus miembros. Es, de hecho, una red institucional sobre el tema juventud en la ciudad y una promotora de redes específicas de tipo temático o funcional a las que sus documentos internos llaman subredes. Paisa Joven define su misión de manera oficial en los siguientes términos: "A nivel organizacional, Paisa Joven posibilita el desarrollo institucional de sus entidades miembro, fortaleciendo su capacidad de gestión y promoviendo sus proyectos; se incide así en la calidad, impacto y pertenencia de sus acciones. A nivel social, como red de entidades que trabajan con jóvenes, busca la concertación mediante la identificación de perspectivas comunes y alianzas estratégicas". Las herramientas de acción adoptadas por Paisa Joven fueron:

- La capacitación y la asesoría en metodologías de planeación, gestión y evaluación de proyectos.

- La sistematización de experiencias reconocidas como exitosas o con gran potencial de ser repetidas.

- La evaluación de políticas, programas y proyectos.

- La difusión de experiencias de trabajo con la juventud, así como de los resultados de sistematización y evaluación.

Para el logro de sus objetivos, Paisa Joven se centra en tres áreas de trabajo, a saber: a) la organización juvenil para el fortalecimiento de los procesos de convivencia y participación ciudadana; b) la educación, como una vía para ampliar y mejorar la intervención de las instituciones que apoyan procesos de participación escolar y el diseño de modelos pedagógicos, y c) la capacitación y promoción para el empleo, que intenta mejorar la calidad de los programas de promoción y adiestramiento para el trabajo de jóvenes (Ramírez, 1999). 
a algunas congregaciones religiosas (jesuitas, franciscanos, dominicos, salesianos, etcétera). Algunas oNG dedicadas a trabajo social han evolucionado hacia otro tipo de prestaciones, entre ellas, la capacitación para el trabajo. Dentro de éstas podemos citar al Centro de Profesionales para la Acción Comunitaria (CEPPAC) ${ }^{13}$ y la Fundación Cristo Vive, ${ }^{14}$ de Chile; así como el Polígono Industrial Don Bosco ${ }^{15}$ de Guatemala. También reciben financiamiento internacional (de organismos de cooperadión) y local (proveniente de iglesias y otros organismos), así como del gobierno. La motivación de su participación está muy vinculada no sólo con la formación para el trabajo de los jóvenes sino también con la transmisión de valores, cuya fuente la constituye la doctrina social de la Iglesia. Definen la población atendida en tér-

${ }^{13}$ El Centro de Profesionales para la Acción Comunitaria (CEPPAC) es una corporación de derecho privado que en el pasado estuvo ligada al trabajo social con la Iglesia católica, se disolvió en 1990, transformándose en 1991 en organización no gubernamental. El CEPPAC desarrolla actividades en el área sur poniente de Santiago en Chile (comunas de El Bosque, San Bernardo, La Pintada y Buin) y está orientado a actividades de desarrollo de la familia popular. Desarrolla dos áreas de trabajo: una que es el área niños, en donde funciona un programa que es de apoyo a los niños y adolescentes trabajadores (este programa tiene distintas líneas de apoyo: apoyo familiar, escolar, talleres de formación, de recreación). La otra área está vinculada con la capacitación laboral. Al interior de ésta hay tres programas: uno dirigido a los microempresarios; otro destinado a las mujeres, principalmente a jefas de hogar; y uno más de capacitación laboral de jóvenes.

${ }^{14}$ La Fundación Cristo Vive es una organización privada sin fines de lucro, dedicada a la educación y a la promoción social de sectores de escasos recursos. Entre sus principales iniciativas figura la Escuela de Formación Profesional de Oficios creada en 1990, luego de una experiencia en el área de oficios para jóvenes y mujeres participantes en campamentos de verano, durante la década de los ochenta. La escuela ha recibido recursos de la cooperación internacional y de fundaciones privadas de desarrollo social, lo que le ha permitido contar con un establecimiento de seis mil metros cuadrados construidos y con muy buen equipamiento. Ubicada en la zona norte de Santiago, la escuela de Cristo Vive cubre principalmente las comunas de esa zona, sin embargo crecientemente ha ido incorporando también jóvenes de otras comunas más alejadas.

${ }^{15}$ El Polígono Industrial Don Bosco (PIDB) es una institución privada de carácter educativo y de proyección empresarial, animada por religiosos de la Congregación Salesiana. Tiene su sede en la ciudad de Guatemala. EL PIDB está ubicado en el municipio de San Salvador en medio de nueve comunidades marginales. Su orígen se ubica en el oratorio festivo del ex Colegio Don Bosco de San Salvador. Nace, a partir de un encuentro real y cercano de la comunidad salesiana con los miembros de las comunidades aledañas al Colegio Don Bosco, como una alternativa de 
minos generales por su condición de extrema pobreza y su situación de excluidos de la educación formal.

Un cuarto y último grupo está formado por organizaciones civiles, con características más locales, ${ }^{16}$ vecinales (tipo centros comunitarios), las cuales, según la descripción de Claudia Jacinto (1998), realizan una oferta de atención social variada que incluye a jóvenes a partir de una fuerte inserción territorial. Es el caso de las ong que además de brindar atención alimentaria y sanitaria, o cuidado de niños pequeños en

desarrollo ante la situación de extrema pobreza que viven las familias de la zona. El complejo empresarial, que reúne empresas cooperativas conformadas por miembros de la comunidad, se instaló en 1986. A partir de esta iniciativa colectiva, se empieza a gestar el proyecto integral que ofrece el PIDB a sus beneficiarios. La misión del PIDB es propiciar el desarrollo de los jóvenes desfavorecidos partiendo de un nuevo modelo empresarial. Ofrece a sus jóvenes beneficiarios un camino de desarrollo integral, basado en la doctrina social de la Iglesia. Este concepto de desarrollo está ligado al nuevo modelo de empresa, también inspirado en la doctrina social de la Iglesia, que tiene como finalidad no simplemente la producción de beneficios, sino más bien la existencia misma de la empresa como comunidad de hombres, que, de diversas maneras, buscan la satisfacción de necesidades fundamentales y constituyen un grupo particular al servicio de la sociedad entera. La integralidad que ofrece el PIDB es uno de los elementos innovadores que lo coloca como una opción para los jóvenes más desfavorecidos. Sus acciones están divididas en distintas áreas: área de educación formal, que atiende a la comunidad educativa del Instituto Técnico Obrero Empresarial (ITOE); área de educación de jóvenes en dificultad; área de animación comunitaria y ecológica; área de salud; área de proyectos de desarrollo (Espinoza Miranda; Pérez; Smutt, 1999:22). ${ }^{16}$ Viva Río es una ONG surgida en 1993 en Río de Janeiro a partir del impacto de dos acontecimientos traumáticos: el asesinato de ocho niños de la calle que dormían junto a una iglesia en el centro de la ciudad y el asesinato de 22 habitantes de una villa-miseria en la zona oeste, ambos cometidos durante la madrugada por policías. Frente a estos acontecimientos que exponían dramáticamente la violencia a que la ciudad estaba sometida, surge un grupo de personas de los más variados segmentos de la sociedad civil (empresarios, sindicalistas, intelectuales, líderes comunales, deportistas, artistas, etc.) interesado en buscar soluciones que pudiesen revertir, a corto plazo, la situación en la ciudad. La misión de Viva Río se resume en las expresiones "paz para la ciudad" e "integración de la ciudad". Coherentes con la misión propuesta, las acciones de Viva Río intentan alcanzar los siguientes objetivos: a) difundir signos de paz asociados a agendas positivas, a través de campañas que involucren a toda la ciudad; b) fomentar el desarrollo comunal a través de la oferta de crédito y asistencia técnica a proyectos de microempresas en villas miserias y barrios pobres; c) conjugar seguridad pública y derechos humanos; d) promover la educación de jóvenes y adultos, como opción estratégica con sentido movilizador, ya que la juventud pobre y poco escolarizada vive en riesgo de marginalidad, como consecuencia de las restricciones de acceso a los mercados de trabajo y a la ciudadanía (Fernández, 1993:3). 
guarderías, muchas veces, a partir de la demanda de la propia comunidad, organizan una capacitación para jóvenes. La función del trabajo voluntario es muy significativa en este tipo de organizaciones.

En América Latina este último grupo se constituye como el más amplio, por el número de organizaciones que hay en cada país. No poseemos estimaciones precisas dela cantidad deon quedesarrollan programas dirigidos a jóvenes pobresen capacitación laboral . Por ejemplo, en A rgentina, Macri (1995, citado por Jacinto, 1998: 39) menciona que según una estimación en 1991, había al rededor de 100 en todo el país. En 1994, en un rel evamiento efectuado para tal fin, se detectaron 28 ong en Capital Federal y Gran Buenos Aires. En Brasil, para la implantación del Programa deServicio Social Voluntario predominaron las oNG (42\%) y las asociaciones de pobladores (41\%), habiendo también iglesias y otros centros religiosos (13\%) y sindicatos (4\%) (A yrton y Mazzotti, 2002:377).

b) Enfoques, estrategias de intervención y diseño de instrumentos

Un enfoque vinculado con la formación profesional dirigida más a adultos y a trabajadores en activo -por lo general con elevada escolaridad- es el de los programas desarrollados por las cámaras empresariales (el primer grupo descrito en la tipología de las organizaciones). Aunque en algunas oportunidades participan jóvenes, éstos son pocos en relación con el total de los capacitados, sin que exista un enfoque claro hacia los jóvenes pobres marginados del trabajo. Es necesario señalar que estas instituciones tienen una muy buena articulación institucional con las empresas que ellos mismos representan, garantizando de esta manera una estrecha relación entre sus necesidades y la formación que se brinda.

Uno delos aspectos novedososy destacados delas osc es el relacionado con el concepto de enfoque integral dela formación para el trabajo. $O$ sea, un tipo de formación que no sólo considera la formación técnica para el trabajo sino queserefiereademás al tipo devalores, actitudesy visión del mundo que se promueve entre los jóvenes que participan. Es el enfoque que en general desarrollan los otros tres grupos de osc descritos anteriormente. 
Con estetipo deenfoque se desarrollan competencias interactivas, más de tipo social y gerencial, para promover entre los jóvenes su capacidad de iniciativa, ya sea para insertarse en el mundo laboral o para poder vivir en armonía con el mundo quelos rodea. A su vez, el desarrollo de capacidades como la iniciativa, la empatía, el don de mando, la disposición a asumir responsabilidades, la creatividad, la responsabilidad, el saber expresarse y relacionarse con los demás, y el trabajar en equipo les permite reconocer oportunidades de trabajos y negocios, así como desarrollar capacidades empresariales personales.

La capacitación laboral brindada por estetipo deorganizaciones se acompaña general mente del tratamiento reflexivo y colectivo detemas relevantes parala juventud: embarazo adolescente, drogadicción, sida, etc. Estetipo de enfoque tiene que ver, además, con la contención social delos jóvenes queparticipan. A simismo desarrolla una noción del trabajador congruente con una visión integral del ser humano. El trabajador es percibido como sujeto económico, político y cultural, con derechos, es decir, como ciudadano dentro deuna visión amplia dela democracia eintegral dela ciudadanía.

En este enfoque las estrategias de intervención general menteson implantadas a partir de módulos cuyo objetivo es abordar precisamente contenidos básicos como comunicación, lectura, cál culo y habilidades sociolaborales. Los módulos diseñados para el desarrollo de estas habilidades básicas tienen en cuenta también aspectos demandados desde el sector empresarial, considerados carentes en los jóvenes provenientes de hogares pobres y que buscan su primer trabajo, y comprenden hábitos como la puntualidad, el aseo, la presentación personal, entre otros. Se incluye además el estudio de normativas laborales y ejercicios para la búsqueda de empleos. El desarrollo de estas habilidades y prácticas ayuda a los jóvenes provenientes de hogares pobres, incapaces de poder continuar estudios superiores, a desarrollar conductas que les ayudarán a insertarse en el mundo del trabajo.

Las osc no descuidan en sus programas los enfoques orientados ala necesidad degarantizar un acceso adecuado y una permanencia delos jóvenes en el sistema educativo formal, lugar donde pueden conso- 
lidar las competencias básicas. En varias experiencias hemos encontrado como estrategia para este tipo de enfoque el desarrollo de módulos específicos que consideran algún nivel de la educación formal (Polígono Don Bosco, Foro Juvenil). Estas intervenciones, por lo general, tienen su origen en la búsqueda de una respuesta a quienes abandonan el sistema educativo con el objetivo de ayudarles a una reinserción en el mismo que les permita completar los ciclos básicos; por ejemplo Viva Río, donde se considera la preparación de exámenes para la aprobación de la educación básica.

El enfoque vinculado más con aprendizajes técnicos dela capacitación se desarrolla mediante módul os orientados tanto a la enseñanza de las habilidades como al reconocimiento y manejo de los procesos laborales, las herramientas y los equipos. Sin embargo, "Ia capacitación técnica parece moverse en el medio de una continua tensión enmarcada por un contexto laboral difícil, quegenera escasas posi bilidades deempleo, y demanda cada vez mayores calificaciones" (Jacinto, 2002:29).

Las pasantías en lugares de trabajo fueron una opción para resolver estas tensiones y resultaron de gran importancia para la primera experiencia delos jóvenes con el mundo del trabajo; es una manera de insertar a los jóvenes en ambientes real es de trabajo. Las pasantías están pensadas como técnicas de apoyo a la inserción laboral. De esta manera el joven tienela oportunidad deprofundizar y poner en práctica aspectos abordados en los cursos, así como superar las adversidades que se le van presentando. En al gunos casos se realizan una vez terminados los otros módulos, aunque se han realizado experiencias de aplicación simultánea de ambas, intercalando días en aula y días en empresas. Los jóvenes reciben generalmente una remuneración equivalentea la de un trabajador dela categoría en quesedesempeña, pero sin incluir las aportaciones y los beneficios de la seguridad social. La obligación de pasantías formó parte de los programas de Proyecto Joven en Argentina, de Planfor en Brasil y de Chile Joven en Chile. Las pasantías permiten a los jóvenes de sectores pobres acercarse a las empresas; "si bien el acceso a empresas legales y formales no entraña necesariamentela iniciación decarreras cal ificantes. En muchos casos se observa que la inserción se realiza en empleos precarios de 
corta duración que, en el corto plazo, significan el retorno al sector informal y más marginal de la economía" (Gallart, 2001:80). Muchos empresarios aún no reconocen este proceso como una vía para favorecer y sel eccionar recursos humanos nuevos para su empresa. Incluso hay empresas que persiguen con las pasantías ahorrar costos delas aportaciones sociales y trabajar con mano de obra barata.

No hay por parte de las osc una fuerte articulación con el sector productivo formal y con las empresas de este sector en particular. El problema fundamental que enfrentan estas osc en sus diferentes esfuerzos devinculación con el sector productivo es la local ización desu población objetivo en el sector informal dela economía o en esas "zonas grises" cada vez más amplias que describeTokman (2004) deempresas que combinan una gran cantidad de rasgos informales con algunos formales. De ahí se deriva uno de los grandes dilemas para estas osc (Tokman, 2004; Gallart, 2004): cuál es el tipo decompetencias para el trabajo que debe impartirse a esta población. Pareciera quelas osc han optado por impulsar una relación desolidaridad o humanitaria más que pensada para asegurar la pertinencia dela formación y el aprendizaje quesepersiguecon las pasantías.

El seguimiento delos egresados decasi todos los cursos queimparten las osc es prácticamente inexistente, salvo en algunos programas donde esto es exigido por las entidades financieras (sobre todo organismos internacionales). En estos casos responden a mediciones puntuales de impacto sobre la cantidad de jóvenes insertos en trabajos al terminar los cursos. No hay estudios de trayectorias individuales de egresados que nos den cuenta del impacto sostenido en el tiempo. La evaluación que hacen Gallart (2004) y Ramírez (2004) permite señalar quelos resultados han sido débiles einsuficientes.

Por su misma flexi bilidad estas organizaciones desarrollan también programas orientados a estimular el trabajo autónomo y la creación de microempresas. Para esto se desarrollan estrategias de capacitación laboral en y para el trabajo independiente:

Los propios beneficiarios manifestaron reiteradamentesu interés y sus proyectos en relación con el trabajo independiente y se registraron esfuerzos de al gunos de los egresados en ese 
sentido (en al gunos casos, frente al poco atractivo que presentaban las ofertas para convertirse en asalariados) (Lasida, y Berrutti, 2002:79).

Sin embargo, respecto a aquellas experiencias que se dirigen al autoempleo o a microemprendimientos tuvieron dificultades: por una parte para encontrar nichos de actividades rentables, y por otra, la sustentabilidad económica deestas actividades en contextos económicos difíciles se hizo más problemática.

Para el diseño de los instrumentos de los programas de formación para el trabajo, las osc recurrieron a diversas fuentes de aprendizaje. La Red Latinoamericana de Educación y Trabajo y CINTERFOR/ OIT con sus investigaciones, sistematizaciones, reuniones, congresos y publicaciones aportaron reflexiones teóricas que sirvieron de base para la elaboración de métodos e instrumentos relacionados con la temática. Otra institución de la región que brindó asesoría, difusión de actividades, oportunidades de pasantías y que también fue importante por los aprendizajes y las metodologías aportadas fueel Centro de Investigación y Desarrollo (Cide) deChile. Estas instituciones ofrecieron instrumentos probados en programas demayor al cance, lo quemotivó a las organizaciones nacional es a sintetizar sus experiencias y transformarlas en model os a escala (reproducibles en otros contextos) y difundirlas con la edición de manuales. ${ }^{17}$

\section{El caso de M éxico}

Si compararamos la importancia de las osc que participan en programas deformación para el trabajo en América Latinay el Caribe, encontraríamos que México se ubica en un extremo opuesto respecto a los demás, ya que tanto la gestión como la ejecución de los programas es todavía estatal, con una acción muy minoritaria de las organizacio-

${ }^{17}$ Es el caso de la elaboración del manual O rientación ocupacional de jóvenes: guía para educadores (1996), probado, evaluado y ajustado por el Foro Juvenil y traducido al portugués. 
nes. Los demás países, como hemos observado por las experiencias descritas, ocupan una situación intermedia al participar junto a otros actores, pero en los cuales las organizaciones civiles tienen ya un protagonismo importante.

En México, en cambio, a pesar del surgimiento y la visibilidad que fueron adquiriendo las organizaciones civiles en ámbitos como el de derechos humanos, atención a niños de la calle, alternativas de salud, proyectos de desarrollo de comunidades, ecologistas, movimientos indígenas, ampliación de los derechos democráticos, son pocas las organizaciones dedicadas a los jóvenes y a la formación para el trabajo. No hay, por tanto, evaluaciones que permitan comparar estrategias y resultados respecto a otro tipo de intervenciones.

Sin embargo, hemos podido revelar, revisando documentos ${ }^{18}$ y realizando entrevistas, algunas experiencias, si bien tal vez incipientes y todavía desarrolladas a nivel exploratorio. Nos limitaremos a citar y describir al gunas de ellas. Los criterios de selección tuvieron que ver con aproximaciones posibles al universo total. Además, dado que no hay una vasta cantidad deexperiencias, lasqueformaron partedenuestro universo ${ }^{19}$ de estudio son representativas, aunque no tanto por

\footnotetext{
${ }^{18}$ I poderac y Programa de A poyo Integral a Ia Infancia Callejera. “Descripción del quehacer", Atlixco, 1998, mimeo; "Nueva propuesta educativa de Ipoderac. Versión preliminar", Atilxco, 2002, mimeo; "Informe de la Evaluación de Impacto", Atlixco, 2000, mimeo; I poderac. "Memoria de Reflexión Crítica núm. 14", Atlixco, 1999, mimeo; "Coordinación de Trabajo de Ipoderac. Planeación estratégica: Fase 1", Atlixco, 2000, mimeo; Enrique Pieck, en el libro Formación, pobreza y exclusión (2000), en el capítulo dedicado a México, La capacitación para jóvenes en situación de pobreza. El caso de M éxico, en p. 351, describe la experiencia de Jóvenes para el Cambio del Fondo de Valle de Bravo y Solidaridad (Fovaso). Para el estudio de la Cocoefo la experiencia fue revisada con documentos proporcionados por la organización Estudios Estratégicos del Sector Comunitario Forestal del Estado de Oaxaca, Cocoefo, 2002, mimeo y para el Cesder Benjamín Berlanga: “Educación y trabajo: la experiencia del Centro de Estudios sobre el Desarrollo Rural (Cesder), México, en la formación técnica y profesional de jóvenes campesinos e indígenas", 2002, mimeo. Para las experiencias en la ciudad de León, Guanajuato: Cámara dela Industria del Calzado y el CIPEC, se realizó trabajo de campo en el lugar (Girardo, 2003).

${ }^{19}$ La Cámara de la Industria del Calzado de León (Guanajuato). Tiene sus orígenes en 1926, cuando se constituyó la Unión de Fabricantes de Calzado de León. La inscripción a la cámara es voluntaria y sólo lo hacen los empresarios que consi-
} 
los programas desarrollados sino porque son casi las únicas que abordan esta problemática a nivel nacional.

Siguiendo con el orden de análisis de dichas organizaciones, podemos destacar que en el grupo seleccionado para estudiar las instituciones en México hay: una cámara empresarial, una ong de tendencia católica y organizaciones con características más locales, tipo centros

deren encontrar algún beneficio para su empresa y trabajo. El número de socios afiliados hasta diciembre de 1999 fue de 1 012. La cámara se presenta, por todas las actividades que desarrolla, muy dinámica para el sector (ya sea por la organización y participación en ferias nacionales y en el extranjero así como por la organización de cursos de capacitación y la difusión de innovaciones tecnológicas).

El Centro de Investigación y Promoción Educativa y Cultural, A.C. (CIPEC). Organización privada no gubernamental, de carácter educativo, con fuerte proyección en el área de formación para el trabajo. Está ubicada en la ciudad de León (Guanajuato), donde desarrolla sus actividades. Tuvo su orígen en 1986, tomando como modelo a las Universidades Laborales de España.

El Instituto Poblano de Readaptación, A. C., (Ipoderac). Organización civil fundada en 1968 que opera en una granja Ilamada Villa Nolasco, en el municipio de A tilxco, a 30 kilómetros de Puebla. Cuenta con una propuesta educativa que parte de estrategias pedagógicas y la práctica del trabajo como espacio de formación. Las actividades del I poderac cuentan, debido a la naturaleza de empresa social del instituto, con objetivos relacionados tanto con la formación de sus educandos como con el sostenimiento económico de la organización.

Fondo de Valle de Bravo y Solidaridad (Fovaso). Organización no gubernamental que opera en el Estado de M éxico. El programa que analiza ofrece un esquema de bachillerato de desarrollo comunitario que a su vez capacita para y en el trabajo a los jóvenes de bajos recursos. Se adapta el currículum al modelo exigido por la Secretaría de Educación pero con innovaciones propias de un bachillerato orientado al desarrollo comunitario. A su vez, intenta promover la participación ciudadana.

La Coordinadora de Comunidades y Ejidos Forestales del Estado de Oaxaca (Cocoefo). Es una organización no gubernamental que inició en 1991, de la cual forman parte 31 comunidades forestales. Trabajan sus proyectos junto con la Asesoría Técnica a Comunidades Oaxaqueñas (Asteco), asociación civil que da asesoría y capacitación a las comunidades para que manejen su empresa comunal y puedan tomar mejores decisiones. También cuentan con programas de educación para alumnos de primaria y secundaria para comunidades indígenas y programas de capacitación laboral, así como programas comunitarios de salud, medio ambiente, etcétera.

El Centro de Estudios sobre Desarrollo Rural (Cesder). Organización no gubernamental que desde 1982 impulsa, en la Sierra Norte del estado de Puebla, una serie de proyectos y programas de trabajo, estructurados actualmente en un Plan Indicativo de Desarrollo Regional. Esta labor se realiza en conjunto con productores, familias, comunidades y organizaciones sociales de los municipios de Zautla e Ixtacamaxtitlán (Puebla). 
comunitarios, descritas como el cuarto grupo en el apartado anterior, donde abordamos el perfil institucional de las organizaciones.

El perfil de la población atendida por la Cámara de la Industria del Calzado en León corresponde a obreros (en realidad muy pocos) y cuadros medios calificados, así como directores y empresarios del sector. Por lo general esta institución trabaja con jóvenes ya insertos en el mercado de trabajo y en alianza con la Universidad Tecnológica de León, los Conaleps y el Cipec, así como con el Instituto Nacional para la Educación de los Adultos (INEA). Asimismo forma parte muy activa del Centro de Vinculación Empresarial del Estado de Guanajuato, mismo que impulsa la interacción de diferentes actores, el gobierno del estado, las universidades públicas y privadas y las cámaras, para un mejor desarrollo de la capacitación laboral. Las demás organizaciones atienden fundamentalmente población urbana de bajos recursos, como jóvenes pandilleros o minusválidos, muchos de los cuales se caracterizan por su deserción del sistema escolar o por no contar con ningún tipo de capacitación que los habilite para entrar al mundo laboral. En el caso del Cipec también dictan cursos a trabajadores en las empresas que ya están trabajando para su actualización. Otras instituciones, como el Ipoderac, dirigen más su atención a jóvenes que han vivido en situación de calle o bien en riesgo de "callejerización". Por último, también están las organizaciones que dirigen su atención a jóvenes y familias con fuerte arraigo en sus comunidades, el Cesder y la Cocoefo.

En cuanto a sus enfoques, estrategias de intervención y diseño de instrumentos, por lo general desarrollan una concepción de formación con una orientación integral humana, muy vinculada con el desarrollo de valores y estrategias de comportamiento social, concepción muy valorada por el Cipec, cuyo objetivo es que los jóvenes encuentren referentes concretos a la práctica de los valores en el mundo del trabajo, así como la capacitación para el trabajo que considera el desarrollo de conocimientos y habilidades técnicas previsibles para la inserción en el mundo laboral, estrategia que implementan junto con un esquema estructurado en el desarrollo de habilidades básicas, genéricas y específicas. El Cipec cuenta con talleres muy equipados que les permite simular procesos de organización y producción. Esto permite que 
los cursos se desarrollen en forma de taller, donde los participantes van aplicando los contenidos a situaciones concretas por medio de simulaciones prácticas que a su vez después ejercitan con pasantías en las empresas. Esta organización cuenta con el apoyo de empresas de la ciudad y del gobierno municipal para establecer programas específicos según algunas necesidades de la ciudad; de esta forma, atienden demandas puntuales por parte de al gunos sectores específicos, como el sector del calzado y el textil, lo cual permite establecer buenos procesos de inserción laboral.

Otras instituciones estudiadas adoptan el modelo deformación en y para el trabajo, como el Ipoderac, organización que desarrolla formación en jardinería, establo de cabras, carpintería y elaboración de jabones. El modelo se basa en cuatro dimensiones de aprendizajes: la técnica, la administrativa organizacional, la relacional y la resolución de problemas. La experiencia de Fovaso, en cambio, representa una al ternativa de reincorporación delos jóvenes y retención dematrícula a la educación media superior y, por otra parte, capacita para el trabajo, tanto a nivel de promotores del desarrollo dela comunidad como a nivel de la formación y conducción de microempresas. El programa que Fovaso realiza ofrece un esquema de bachillerato de desarrollo comunitario. El currículo está adaptado al modelo exigido por la Secretaría de Educación pero con las innovaciones propias de un bachiIlerato orientado al desarrollo comunitario. Por otra parte, la Cocoefo y el Cesder trabajan en asesoría y capacitación a las comunidades en para que éstas manejen empresas sociales y desarrollen capacidades degestión y administración. Cuentan también con programas deeducación para alumnos de primaria y secundaria de comunidades indígenas y con programas de capacitación para mujeres indígenas. Estas organizaciones buscan desarrollar model os educativos adecuadosa las condiciones de vida de regiones agricultoras pobres para responder a necesidades específicas. Como muchas delas ong dela región y como organizaciones pequeñas que son, los resultados en cuanto a la sistematización de experiencias de todas ellas son bajos, así como la producción teórica, ya que están limitadas por las exigencias mismas del trabajo con las comunidades y por el esfuerzo que real izan en la búsqueda deapoyos financieros para sostener los programas. 
Con la descripción general de estas organizaciones destacamos nue vamente la poca presencia de este tipo de experiencias en el campo de la formación de jóvenes en México; prácticamente la oferta total continúa en manos del gobierno. Quizá haya muchas experiencias locales silenciosas, no sistematizadas ni evaluadas pero quegeneran una formación para el trabajo puntual y están vinculadas con el contexto productivo local, con un impacto bastante importante en la población atendida, que sin embargo no han sido revel adas hasta ahora por investigaciones académicas. Esto pone de manifiesto dos cuestiones: o hay poca inquietud por parte de la sociedad civil por este ámbito dela educación, o las experiencias realizadas en las ciudades por organizaciones civiles no han llegado a tomar la fuerza y el impacto necesarios para atraer la atención de los investigadores y estudiosos del tema.

\section{Fortalezas y debilidades}

La investigación también permite detectar las fortalezas encontradas en las osc como diferenciadores en estetipo de organizaciones respecto a otras pertenecientes ya sea al Estado o al mercado, en la formación para el trabajo delos jóvenes.

\section{a) A tienden a grupos desfavorecidos y excluidos del sistema}

Las organizaciones estudiadas destacan por su atención a jóvenes con deficiencias en la educación básica, con pocas oportunidades para ingresar en el mundo del trabajo, o que ya están insertos en él, pero en trabajos informales o de mala calidad. A pesar de que definen a su población objetivo bajo la generalidad de jóvenes desfavorecidos, es importante señalar el grado de heterogeneidad en cuanto al perfil de Iosjóvenes atendidos: en muchos casos setrata dejóvenes en situaciones de gran marginalidad (chicos de la calle) o marcado aislamiento (indígenas), en otros el perfil de los jóvenes se encuadra en sectores urbanos que tienen una situación de pobreza estructural o han sido recientemente pauperizados. Los programas desarrollados por estas organizaciones están enfocados a revertir o atenuar esta pro- 
blemática, acciones imprescindibles en la conformación de ciudadanos plenos de derechos. Su focalización hacia los más pobres plantea además una relación con las políticas dirigidas a atenuar la pobreza.

b) Desarrollan estrategias de formación innovadoras y más integrales

Las estrategias de formación desarrolladas por las osc estudiadas evidencian que las mismas van mucho más allá de los cursos de formación profesional específica. Estas organizaciones, como hemos podido observar del estudio de sus programas, incluyen componentes diversos que plantean una formación más amplia, más integral, especialmente en lo concernienteal desarrollo de aspectos de actitud y sociales.

Las transformaciones estructurales del mundo de la producción, y sus cambios en el mercado de trabajo como producto de la competencia global y del surgimiento y desarrollo de las tecnologías de información y comunicación, incluyen diversos componentes que plantean una nueva concepción del trabajo y, por tanto, un tipo de formación mucho más amplia que la requerida anteriormente. Una noción cada vez más compleja del trabajo involucra además de la tradicional dimensión técnica, competencias de tipo social y gerencial, así como diversas actitudes y val ores ligados a una visión más integral del ser humano. Los programas desarrollados por las organizaciones estudiadas tienden a mitigar el efecto estigmatizador que conllevan algunos jóvenes, como por ejemplo la descalificación social, experimentada al ser pobre o excluido; de esta manera se contribuye $a$ atenuar la rabia y el resentimiento que viven los adolescentes pobres con la exclusión social.

Sus objetivos pretenden compensar el déficit producido por el abandono temprano y por la exclusión del sistema formal educativo. Actúan fundamental mente como factor de prevención y como principal espacio de integración social. Estas organizaciones se proponen un desarrollo más integral del joven, entendiendo por esto una formación que incorpora además de la capacitación para el trabajo la recuperación de valores y principios vinculados con aspectos humanos y sociales. 
c) Tienen buen impacto en la inserción laboral

Los programas desarrollados por las osc, si bien no contamos con datos comparables salvo los disponibles por cada organización, sugieren que los resultados son satisfactorios, pues superan las exigencias mínimas planteadas por dichos programas. Por ejemplo, en el caso deForo Juvenil, "Ias evaluaciones de la focalización, los resultados y los efectos fueron ampliamente satisfactorios en términos de la inserción laboral de los egresados y de la calidad de los empleos obtenidos (respecto a la formalidad, salarios, estabilidad, etcétera)" (Lasida y Berrutti, 2002:127).

\section{d) Establecen la construcción dealianzas estratégicas}

El tema delas alianzas, como una intersección entrelas esferas privadas y estatales (favoreciendo y reconociendo la emergencia denuevos actores, como son las organizaciones de la sociedad civil) desde una nueva concepción de lo público, constituye un importante aspecto innovador. Las alianzas son deliberadamente producidas y se fueron formalizando con convenios de coparticipación al rededor de proyectos concretos, con objetivos, mecanismos y programas específicos. Implican acciones cooperativas, voluntarias y de intercambio. Las alianzas, tanto por las condiciones en quese desarrollan como por sus modalidades y expansión, constituyen un fenómeno relativamente nuevo. Con su construcción se establece una lógica de gestión nueva. Se pasa de un sistema mecánico (de sumas de partes) a un sistema complejo (de interacciones). El actor protagónico no es la organización independiente, sino uno nuevo institucional -la alianza- entre distintos agentes que buscan resolver problemas comunes. Esta sinergia ayuda indudablemente al logro de los proyectos propuestos.

En este nivel las organizaciones se transforman en un nuevo actor social, pues se abandona la simple suma de esfuerzos particulares para "desatar procesos" de transformación de la realidad social. Se habla entonces de un cambio fundamental en la naturaleza y forma de operación de las osc, que pasan a actuar en un plano institucional más alto con distintos actores de los sectores público y privado. 
e) Contribuyen con la construcción de políticas públicas de educación y trabajo

Los programas de formación para el trabajo ejecutados por las osc en la región, a pesar de las debilidades con que aún cuentan, y de las diferencias de cada país, proveen instrumentos y sugerencias que enriquecen y modifican las políticas públicas dirigidas a estimular la promoción de los jóvenes a partir de la formación para el trabajo.

El cambio deposicionamiento de las organizaciones civiles respecto a su nueva relación con el gobierno las coloca en una dinámica de reconocimiento por partedel Estado como interlocutores válidos para la construcción de políticas públicas en temas vinculados con jóvenes, educación y trabajo. Las políticas públicas colocan a las osc en una doble perspectiva: como ejecutoras de servicios y como actores protagónicos de participación social y política de los países. En esta nueva dinámica, setrata demancomunar y concertar esfuerzos, desterrando empeños aislados y excluyentes entre sí.

Las debilidades, en cambio, se refieren básicamentea la identificación de las desventajas que presentan las organizaciones, lo cual nos permite conocer cuáles son las barreras que impiden a las mismas al canzar sus metas y objetivos. La superación de estos límites les permitiría alcanzar mejores desempeños. En nuestra investigación encontramos como retos aún pendientes los siguientes:

\section{I) Baja calidad de la formación brindada}

Los problemas de cal idad son todavía un problema por resolver para al gunos proyectos ejecutados por las osc en la región. La planificación y evaluación reciben atención insuficiente: “la organización tienedificultades para el registro y evaluación de cada experiencia, especialmente en relación con los resultados. Se evalúa lo necesario para tomar decisiones a fin de ajustar las siguientes intervenciones, pero la documentación del proceso no es sistemática y es dispareja" (Foro Juvenil, en Jacinto, 2002:138). Por su parte, como manifiestan los investigadores del Polígono Industrial Don Bosco, "si no asume el reto de organizar, sistematizar y evaluar su experiencia, corre el 
riesgo de diluir sus esfuerzos sin dejar prueba del éxito o el fracaso de su proyecto" (Pérez, Miranda y Méndez, 2002).

Otro problema es que la elaboración de módulos no responde a un estudio específico con la identificación de la demanda a la cual debe responder el curso. Hay en las osc mucho espontaneísmo al ir resolviendo momentos críticos en el desarrollo de los cursos. Quizá por la misma rotación de sus miembros, que van pasando por las organizaciones, tampoco hay acumulación de experiencias que permitan generar aprendizajes dentro de la organización. Así, adaptan materiales y técnicas, pero muchas veces éstas no son aptas para los cursos que están desarrollando. Las organizaciones civiles que participaron en Planfor de Brasil y en Proyecto Joven de Argentina adolecieron de estos límites. Los cursos impartidos por estas organizaciones generalmente partían de cero: de acuerdo con las tareas requeridas elaboraban un programa; y es así como un "siglo de formación" quedaba en la nada, se reinventaba todo (Castro C. de Moura, 2002:201).

Dichas organizaciones tenían poco contacto con las instituciones tradicionales que por años se habían dedicado a la formación para el trabajo, lo cual se tradujo en un enorme esfuerzo para poder construir trayectorias y llevar a cabo la formación, conseguir y formar capacitadores, encontrar los lugares adecuados y establecer contacto con los empresarios para garantizar la inserción, afectando la calidad de la misma.

Las organizaciones en general no se focalizan en la calidad de la formación en sí; como resultado, por ejemplo, la calidad delos insumos, particularmente los materiales usados, disminuyen en calidad. La generación de insumos (libros, materiales y conocimiento), parte importante en la formación brindada por las instituciones tradicionales, van perdiendo calidad. Otros problemas asociados con la calidad dela formación remiten a la dificultad, en muchos casos, delas organizaciones sociales para establecer relaciones con los empresarios. Por muchos años, estas organizaciones mantuvieron una posición ideológica bastanteantagónica con los actores del gobierno y del mercado. Si bien esta posición ha cambiado en los últimos años y ahora se establece mucho más una política deal ianzas y concertación, las organizaciones civiles no cuentan todavía con amplias redes, principal mentecon agen- 
tes del mercado, para detectar oportunidades viables para la inserción de los jóvenes más a largo plazo.

Entreotras dimensiones asociadas con la calidad, aparecela eficiencia y la eficacia. Al respecto se ha sostenido que no resulta sencillo medir la eficacia, ya que si setoman sólo indicadores de resultados relacionados con la inserción laboral de los egresados se excluyen beneficios secundarios relevantes, como la reinserción laboral, la integración social o la autoestima (Ramírez, 1996); "en cuanto a la eficiencia, ésta se remite directamente a los procesos formativos, los equipos docentes, las instalaciones y los equipamientos, es decir, dimensiones que se encuentran en la llamada 'caja negra' de la capacitación y que rara vez han sido analizadas con exhaustividad" (Jacinto y Gallart, 1998:317).

En el caso específico de las osc, la eficacia estaría relacionada más con la contención y compensación social que sele brinda a este sector dela población quecon la propia inserción laboral. En muchas ocasiones, las organizaciones sociales complementan y potencian aún más sus actividades recreativas, deportivas, solidarias, de comunicación, etcétera.

Claudia Jacinto (1998) nos advierte: "en estas organizaciones, la capacitación laboral es un componentemás al queacceden sólo los jóvenes que lo desean y/ o que son considerados en condiciones de efectuar un aprovechamiento de esa clase de entrenamiento". Tampoco pueden evaluarse estas organizaciones por el impacto de sus programas, es decir, por el número de jóvenes atendidos, ya que por tratarse de organizaciones no muy grandes y que cuentan con pocos recursos financieros, generalmente dicho impacto está circunscrito a la poca cantidad de jóvenes. Respecto a la eficiencia, también estaríamos hablando de indicadores bajos, ya que como describimos anteriormente, estas organizaciones no cuentan con equipos docentes preparados de forma adecuada y sus instalaciones son generalmente locales prestados con equipamientos de baja cal idad. ${ }^{20}$

\footnotetext{
${ }^{20}$ A quí habría que señalar que en algunos casos, como por ejemplo la Fundación Cristo Vive de Chile, cuando tienen acceso a recursos aportados por la financiación internacional pueden contar con establecimientos muy buenos y equipamientos de calidad.
} 


\section{II) Escasa formación de formadores}

Las osc invierten poco en sus formadores. Sus presupuestos, en muchas ocasiones escasos como ya dijimos, no les permiten diversificar la formación de sus mismos trabajadores o voluntarios. Si bien en estos últimos años hubo en este tipo de organizaciones una disponibilidad mayor para empezar a profesionalizar a susintegrantes, ésta quizá obe deció más a una profesionalización administrativa más general y no a la capacitación en sí de los formadores que se van involucrando en programas específicos. En muchos casos se trata de profesionistas de las ciencias sociales, sobretodo del área decomunicación y sociología, pero que están encargados de muchas y variadas actividades dentro dela organización. Para llevar a cabo programas de formación para el trabajo no es suficiente la buena voluntad de los militantes en estas organizaciones, sino más bien de lo que se trata es de profesionalizar personal más cal ificado, con formación específica, que produzca materiales y genere aprendizajes que enriquezcan la capacidad organizacional de las instituciones: "particular atención merecen los jóvenes quese preparan para ser educadores desusmismos compañeros. A unque poseen a su favor la riqueza de su propia existencia y el haberla transformado en un ejemplo imitable, estos jóvenes necesitan contar con recursos técnicos mínimos queles faciliteasumir su nuevo papel" (Pérez, Miranda, Mendez, 2002:314). Tampoco hay carreras universitarias impulsadas por el Estado, ni organismos específicos en el entorno de los Ministerios deEducación que se dediquen a la formación de educadores, y en general derecursos humanos para estas estrategias.

Contar con instructores improvisados repercute sin lugar a dudas en la calidad de la formación y trae como resultado malas prácticas y poca experiencia acumulada:

Sería conveniente impulsar acciones con estos objetivos, pero con modalidades de ejecución descentral izadas y diseñadas a partir de consultas y negociaciones con todos los actores que requieren de esos recursos humanos. Al igual que toda la formación profesional, en este caso también se debería ofre cer formación inicial y continua para quienes ya desempeñan sus funciones (Lasida y Berrutti, 2002:146). 
Sin embargo, debemos destacar que en el caso de Viva Río, por ejemplo, los profesionales que participaron en la ejecución de sus programas poséan una formación escolar adecuada, sobrepasando en su mayoría los niveles exigidos para el ejercicio de sus funciones. ${ }^{21}$

\section{III) Poca disponibilidad de recursos financieros}

La mayoría de los casos que hemos revisado son organizaciones con escasos recursos financieros y técnicos. Su financiamiento dependecasi exclusivamente de la ayuda brindada por diferentes organismos de cooperación, principalmente el Estado, y por la cooperación voluntaria y comprometida de al gunas personas que participan en el trabajo de estas organizaciones. Muchas organizaciones, ante la urgencia de obtener fondos, compiten con otras organizaciones civiles por el apoyo financiero del gobierno, estatales, disminuyendo su capacidad de innovación y perdiendo su capacidad de autonomía, lo cual debilita su capacidad para trabajar en red. Lo ideal es contar con nuevas fuentes de financiamiento sin subordinarse ni perder sentido de identidad, así como generar nuevas estrategias de recaudación defondos locales y / o nacionales o autofinanciar por medio de actividades propias.

\section{Conclusiones}

Nuestra investigación se propuso el desafío de contribuir al conocimiento y la sistematización de algunas experiencias importantes de osc de América Latina y el Caribe que orientan sus actividades en formación para el trabajo para mejorar la calidad de vida de jóvenes excluidos desde una gama de perspectivas innovadoras.

Los procesos de descentralización del Estado, la revalorización de los gobiernos municipales y el desarrollo local favorecieron la creación de espacios donde las osc realizan sus acciones o son interlocutoras o puentes entre la sociedad, el gobierno y la administración pública.

${ }^{21}$ El nivel de escolaridad de los profesionales se puede consultar en Ayrton y Mazzotti (2002:395). 
En este sentido, son organizaciones que cumplen una destacada función social. Los resultados obtenidos muestran que su principal misión es compensar, prevenir, equiparar y ayudar a superar las carencias y necesidades de una amplia población juvenil abandonada o excluida de los sistemas formales de educación y trabajo. Para ello proponen un desarrollo más integral del joven, entendiendo por esto una formación que incorpore, además de la capacitación para el trabajo, la recuperación de valores y principios vinculados con aspectos humanos y sociales.

La capacidad para generar alianzas con otros sectores de la sociedad, como el gobierno y los empresarios, ayuda a fortalecer el tejido social, así como a aumentar la disponibilidad de los recursos en el territorio y mejorar la institucionalidad y el aprendizaje local.

En general, por número, constituyen aún una presencia relativa en casi todos los países de A mérica Latina y el Caribe. Cuentan con baja institucionalidad y enfrentan muchos retos aún pendientes.

Las experiencias revisadas en México presentan también aspectos que podemos destacar como alentadores, ya sea por la focal ización de sus cursos a poblaciones marginadas y excluidas como por sus estrategias de formación innovadoras. De manera incipiente están comenzando a focalizar su atención a este aspecto de la formación para el trabajo, en ambientes locales, construyendo alianzas y concertando programas de colaboración con el gobierno. Su constante contacto cotidiano con la problemática de la población, su empatía con los excluidos, su capacidad de denuncia y su habilidad para hacer que la sociedad se interese por problemas no evidenciados por el gobierno, constituyen factores que las convierten en organizaciones con fortalezas para la atención de los jóvenes.

Con todo, estas fortalezas pueden convertirse en puntos débiles, ya que sus enfoques continúan en muchos casos siendo asistenciales, de impacto limitado además de repetir prácticas que si bien fueron eficaces en otras épocas ahora son inoperantes cuando se trata de enfocar programas en temas más especializados y de mayor alcance, como es el caso de la formación para el trabajo de los jóvenes. Es aquí donde las organizaciones en México deben plantearse cambios y propuestas no sólo en términos de compromiso social, sino 
también en su fortalecimiento institucional como un imperativo para participar en la gestión de políticas públicas.

De todas maneras, y a pesar detodos los esfuerzos que aún deben realizar las osc para mejorar sus prácticas y fortalecimiento institucional, constituyen sin duda un referenteque debeser reconocido, reval orizado y potenciado como actores sociales contemporáneos que, junto con otras instituciones, generan programas innovadores deformación para el trabajo en contextos local es. Dejamos abierta nuestra propuesta para futuras investigaciones y reflexiones que sigan aportando para el conocimiento de estas organizaciones y el papel que desempeñan en la construcción de alternativas que enriquecen la participación e inclusión equitativa detodos los jóvenes.

\section{Bibliografía}

Ayrton, Fausto y Alves-Mazzotti. 2002. "El servicio civil voluntario en el Brasil: educación básica, profesional y ciudadana”. En Autores varios. N uevas alianzas y estrategias de la formación para el trabajo de jóvenes desfavorecidos. Estudios de caso en A mérica Latina. UNESCO, febrero.

Borja, Jordi. 1987. D escentralización y participación cuidadana. Madrid, Instituto Nacional dela Administración Pública.

Cabrero Mendoza, Enrique. 1995. La nueva gestión municipal en M éxico. México, CIDE, Porrúa.

Castro, C. de Moura. 2002. Formación profesional en el cambio de siglo. Montevideo, Cinterfor.

Coraggio, José Luis. 1997. D escentralización el día después..., Argentina, Universidad deBuenos Aires.

De Ibarrola, María. 1998. “Educación básica y competencias laborales". En M emoria Seminario Latinoamérica. Bogotá, Colombia. . 1999a. "La formación de los jóvenes no universitarios para el trabajo en el desarrollo regional de México". Proyecto deinvestigación aprobado por Conacyt, enero.

. 1999b. "Las transformaciones delas políticas deformación profesional de América Latina". En Innovaciones en formación. Boletín 147, Montevideo, Cinterfor/ OIT, pp. 113-124. 
Del barrola María. 2000. “Los cambios estructurales y las políticas de formación y capacitación en México". En M emorias del Seminario de Formación y Capacitación ante los R etos que Plantea la A pertura Económica y la Reestructuración de las Empresas.

. 2001. “Los cambios estructurales y las políticas de capacitación y formación para el trabajo en México. Un análisis de la expresión local de políticas nacionales". En Enrique Pieck (coord.). Los jóvenes y el trabajo.

.2002. “Expresión delas accionesy políticas deformación delos jóvenes en y para el trabajo en la industria del calzado de la ciudad". En La formación delos jóvenes no universitarios para el trabajo, en el desarrollo regional de M éxico. Informe final presentado a Conacyt, diciembre.

. 2002. "La industria zapatera. Expresión más importante de la estructura del trabajo dela ciudad". En La formación delos jóvenes no universitarios para el trabajo, en el desarrollo regional de M éxico. Informe final presentado a Conacyt, diciembre. . 2002. Desarrollo local y formación. Montevideo, Cinterfor. . 2002. “Hacia una mirada integral de la formación de los jóvenes para el trabajo". En D esarrollo local y formación.

. 2002. "Nuevas tendencias de la formación para el trabajo". En D esarrollo local y formación.

Espinosa Miranda, L., A. Pérez y M. Smutt. 1999. El Salvador. Polígono Industrial D on Bosco: sistematización de experiencias. Documento presentado en el seminario regional organizado por IIPE, El INA y la UCR, en San José, Costa Rica, del 22 al 25 de noviembre.

Gallart, María Antonia. 1998. “Lo público y lo privado en la formación para el trabajo. Estado de arte en A mérica latina". En M emoria Seminario Latinoamericano. Bogotá.

. 2000. "Nuevas relaciones entre el sector público y privado en A mérica Latina con respecto a la formación, como resultado de los procesos de apertura de mercados y de reestructuración productiva". En M emorias del Seminario de Formación y Capacitación Ante los R etos que Plantea la A pertura Económica y la Reestructuración de las Empresas. 
Gallart, María Antonia (coord.). 2000. Formación, pobreza y exclusión. Montevideo, Uruguay. Oficina Internacional del Trabajo, Cinterfor.

. 2001. "Los desafíos de la integración social de los jóvenes pobres: las respuestas de los programas de formación en A mérica Latina". En Enrique Pieck (coord.). Los jóvenes y el trabajo. . 2002. "Tendencias y desafíos en la interacción entre educación y trabajo". En Delbarrola (coord.). D esarrollo local y formación. 2002. V einte años de educación y trabajo. Montevideo, Uruguay, Cinterfor.

. 2004. "Habilidades y competencias para el sector informal dela economía". En Formación en la economía informal. Boletín Cinterfor, núm. 155, pp. 33-75.

García Delgado, Daniel. 1998. Estado-nación y globalización. Buenos Aires, Ariel.

Girardo, Cristina. 2003. “La formación para el trabajo de los jóvenes (desafíos y estrategias) desdelas organizaciones dela sociedad civil". Tesis de Doctorado en Estudios Latinoamericanos. México, Facultad deCiencias Políticas y Sociales, UNAM.

Jacinto, Claudia y María A ntonia Gallart. 1998. La evaluación de programas de capacitación de jóvenes desempleados. U na ilustración de los enfoques evaluativos en los países del Cono Sur. París, IIPE-UNESCO. . 1995. Capacitación y empleo de jóvenes en A mérica Latina. Montevideo. Cinterfor/ OIT.

. 1997. “Políticas públicas de capacitación laboral de jóvenes en A rgentina. Un análisis desdelas expectativas y las estrategias de los actores". Boletín Técnico Interamericano de Formación Profesional (volumen sobre Jóvenes, formación y empleabilidad), núm. 139-140, abril-septiembre, Montevideo, Cinterfor/ OIT.

. 1998. "Articulaciones y tensiones entre lo público y lo privado. El caso de los programas de formación para el trabajo de los jóvenes". En M emorias Seminario Latinoamérica. Bogotá, Colombia.

y María Antonia Gallart (coord.). 1998. Por una segunda oportunidad. La formación para el trabajo de jóvenes vulnerables. Montevideo, Uruguay, Cinterfor/ oIT. 
Jacinto Claudia 1999. Enfoques y tendencias de los programas de educación dirigidos a niños y jóvenes desfavorecidos en A mérica Latina. Programme de Recherche et d'études: Stratégies d'education et de formation pour les groupes défavorisés. París, IIPE-UNESCO. . 1999. Programas de educación para jóvenes desfavorecidos. Enfoques y tendencias en A mérica Latina. París, UNESCO. . 2001. "Contextos y actores sociales en la evaluación de los programas y capacitación de jóvenes". En Enrique Pieck (coord.). Los jóvenes y el trabajo.

. 2001. Fortalecimiento institucional de entidades de capacitación para jóvenes desfavorecidos. París, IIPE-UNESCO.

. 2002. "Lecciones y encrucijadas en la formación para el trabajo de jóvenes desfavorecidos en A mérica Latina". En N uevas alianzas y estrategias en la formación para el trabajo dejóvenes desfavorecidos. y otros. 2002. N uevas alianzas y estrategias en la formación para el trabajo dejóvenes desfavorecidos. Estudios decaso en A mérica Latina. París, UNESCO.

Lasida, Javier y Elcira Berrutti. 2002. "Foro Juvenil, ensayos y aprendizajes para las políticas de educación y trabajo". En Autores varios. N uevas A lianzas y estrategias de la formación para el trabajo dejóvenes desfavorecidos. Estudios decaso en A mérica Latina. UNESCO, febrero.

Leite, Elenice. 1999. “El festival delos actores en la historia dela nueva institucionalidad dela educación profesional en Brasil: un festejo articulado". En M emoria del Seminario de Formación y Capacitación ante los Retos que Plantea la A pertura Económica y la Reestructuración de las Empresas. México, Conocer, CEPAL, Red Latinoamericana de Educación y Trabajo.

. 2002. "Educación y trabajo. Nuevos actores, viejos problemas". En Del barrola, María (coord.). D esarrollo local y formación: hacia una mirada integral dela formación delos jóvenes para el trabajo. Montevideo, Cinterfor, 236 pp. (Herramientas para la Transformación, 18), pp. 169-210.

N avarro, Juan Carlos. 1998. “Las ONG y la prestación de servicios sociales en América Latina: el aprendizaje ha comenzado". En Bresser Pereira y Cunill Grau. 
Novick, Marta. 1999. Experiencias exitosas de capacitación de empresas innovadoras de A mérica Latina y el Caribe. En Guillermo Labarca (coord.). Formación y empresa.

Pérez, Armín, Lissette Miranda y Mario Méndez. 2002. “Polígono Industrial Don Bosco. Un paradigma educativo". En Varios autores. Nuevas alianzas y estrategias en la formación para el trabajo de jóvenes desfavorecidos.

Pieck, Enrique. 2000. “La capacitación para jóvenes en situación de pobreza. El caso de M éxico". En María A ntonia Gallart. Formación, pobreza y exclusión. (coord.). 2001. Los jóvenes y el trabajo, la educación frentea la exclusión social. México, Universidad Iberoamericana.

Ramírez Guerrero. Jaime. 1999. “Los agentes sociales frente a la formación para el trabajo y la capacitación: intereses, propuestas y estrategias". En M emorias del Seminario de Formación y Capacitación A nte los R etos que Plantea la A pertura Económica y la Reestructuración de las Empresas.

. 1996. “Evaluación de experiencias de formación para el trabajo en Colombia". Documento presentado en el seminario y foro "Formación decalidad parajóvenes desectores depobreza". Montevideo, Foro Juvenil, Cinterfor y Red Latinoamericana de Educación y Trabajo, 25-26 de marzo.

. 1998. “Introducción al Seminario ‘Lo público y lo privado en la formación para el trabajo'". Bogotá, Colombia.

. 1998. “La Formación deTransición: modelo conceptual para una estrategia deintervención contra el desempleo juvenil de tipo estructural". EnJuventud, educación y empleo. Montevideo, Cinterfor. . 1998b. "Los programas de capacitación laboral del modelo 'Chile Joven' en América Latina. Una agenda para el seguimiento". En Jacinto y Gallart. Por una segunda oportunidad. . 1999. "Intervención delos municipios y los actores locales en la formación e inserción laboral de jóvenes. Análisis de varios casos latinoamericanos, con énfasis en la experiencia de la corporación Paisa Joven de Medellín". Documento presentado en el seminario regional organizado por IIPE, el INA y la UCR en San José de Costa Rica, del 22 al 25 de noviembre. 
Ramírez Guerrero, Jaime. 2001. El rol de los actores locales en la formación e inserción laboral de jóvenes: la experiencia de la corporación Paisa Joven en M edelín (Colombia) y otros casos en A mérica Latina. París, UNESCO. IIPE.

. 2004. “Capacitación laboral para el sector informal en Colombia”. En Formación en la economía informal. Boletín Cinterfor, núm. 155, 2004. pp. 77-133.

Reygadas, Rafael. 2002. “Las organizaciones civiles en México: ¿Crisis de un Paradigma? Desarrollo y Tercer Sector. II Seminario A nual delnvestigación sobreel Tercer Sector. CEM EFI (Centro M exicano para la Filantropía) (1990)". La filantropía mexicana: diagnósticos y propuestas. México. Colegio Mexiquense. Centro Mexicano para la Filantropía.

Rivera, Roy A. 1996. D escentralización y gestión local en A mérica Latina. San José. Costa Rica, FLACSO.

Tokman, Víctor. 2004. "Delainformal idad ala modernidad". En Formación en la economía informal. Boletín Cinterfor, núm. 155, pp. 9-31.

Vázquez Barquero. 1993. D esarrollo económico local. Madrid, Pirámide.

Artículo recibido en agosto de 2003. A rtículo aprobado en noviembre de 2003. 
